\title{
Phosphorylation Status of Regulatory Proteins and Functional Characteristics in Myocardium of Dilated Cardiomyopathy of Syrian Hamsters
}

\author{
Yoshiki OHNUKI ${ }^{1}$, Satoshi NISHIMURA ${ }^{2}$, Seiryo SUGIURA ${ }^{3}$, and Yasutake SAEKI ${ }^{1}$ \\ 1Department of Physiology, Tsurumi University School of Dental Medicine, 2-1-3 Tsurumi, Tsurumi-ku, Yokohama, 230-8501 Japan; \\ 2Department of Cardiovascular Medicine, Graduate School of Medicine, and ${ }^{3}$ Biomechanics Laboratory, Institute of Environmental \\ Studies, Graduate School of Frontier Sciences, University of Tokyo, Bunkyo-ku, Tokyo, 113-0033 Japan
}

\begin{abstract}
To understand the pathophysiology of hereditary cardiomyopathy, we measured the phosphorylation status of regulatory proteins, troponin I ( $\mathrm{Tnl})$, troponin $\mathrm{T}(\mathrm{TnT})$, myosin light chain 2 (MLC2), and myosin-binding protein C (MyBP-C), and the $\mathrm{Ca}^{2+}$-dependence of tension development and ATPase activity in skinned right ventricular trabeculae obtained from cardiomyopathic (TO-2 strain, $n=8$ ) and control (F1B strain, $n=8$ ) hamsters. The $\mathrm{Ca}^{2+}$ sensitivities of tension development and ATPase activity (mean \pm SD) were significantly $(P<0.0001)$ higher in the TO-2 strain $\left(\mathrm{pCa}_{50} 5.64 \pm 0.04\right.$ in tension and $5.65 \pm 0.04$ in ATPase activity) than in the $\mathrm{F} 1 \mathrm{~B}$ strain $\left(\mathrm{pCa}_{50} 5.48 \pm 0.03\right.$ in tension and $5.51 \pm 0.03$ in ATPase activity). No significant differences in their maximum values were observed between TO-2
\end{abstract}

$\left(40.8 \pm 7.4 \mathrm{mN} / \mathrm{mm}^{2}\right.$ in tension and $0.52 \pm 0.15 \mu \mathrm{mol} / / \mathrm{/s}$ in ATP consumption) and F1B $\left(42.3 \pm 8.5 \mathrm{mN} / \mathrm{mm}^{2}\right.$ in tension and 0.58 $\pm 0.41 \mu \mathrm{mol} / / \mathrm{/s}$ in ATP consumption) preparations, indicating that the tension cost (ATPase activity/tension development) in TO-2 was quite similar to that in F1B. The phosphorylation levels of MLC2 and Tnl were significantly $(P<0.01)$ lower in TO-2 than in F1B. These results suggest that the increase in the $\mathrm{Ca}^{2+}$ sensitivities of tension development and the ATPase activity in TO-2 hearts result from the decreased basal level of Tnl phosphorylation, and these features can be considered to produce the incomplete diastolic relaxation and partly improve the systolic function in TO-2 hearts.

Key words: dilated cardiomyopathy, phosphorylation status, tension development, ATPase activity, tension cost.

$\mathrm{D}$ ilated cardiomyopathy (DCM) is a primary heart muscle disease characterized by ventricular dilation and systolic dysfunction [1]. Bio TO-2 strain hamster with congenital DCM shows similar clinical backgrounds to human cases and thus has been considered to be a representative animal model of human hereditary dilated cardiomyopathy [2-7]. The gene defect in $\delta$-sarcoglycan has been identified as being responsible for DCM in TO-2 hamster [8,9] as well as in human [10]. To understand the pathogenesis of this animal model and the pathophysiology of heart failure, the hemodynamic characteristics have been analyzed at the organ level $[2,4]$. The subcellular mechanism accounting for the myocyte dysfunction, however, remains to be characterized, though it is reported to very likely include the abnormalities of the sarcolemma, the sarcoplasmic reticulum, and the myofibrils [11-13]. Recently, we [7] studied the contractile function of myocytes isolated from the ventricles of 10- to 12-week-old TO-2 hamsters over a wide range of loading conditions and found that (1) in the unloaded condition, the shorten- ing fraction and maximum shortening velocity were decreased in TO-2 myocytes as compared with normal control (F1B strain hamster) myocytes; (2) the peak force in the isometric condition and the external work in physiologically loaded conditions were also decreased. Being consistent with these contractile dysfunctions, the calcium transients measured by Indo- 1 were found to reveal an elevated diastolic level, a decreased peak level, and a slower diastolic decay in TO-2 myocytes as compared with F1B myocytes. Taken together, these results strongly suggest that the contractile dysfunctions in a TO-2 heart are largely caused by the impairment of the sarcoplasmic reticulum calcium transport function. Supportive evidence has been reported in dilated cardiomyopathic hamsters (Bio 53.58), which are identical to TO-2 hamsters $[12,13]$. However, the myofibrilar contribution to the contractile dysfunction in TO-2 heart remains to be studied.

We therefore analyzed the phosphorylation status of regulatory proteins, myosin light chain 2 (MLC2), tropo$\operatorname{nin} \mathrm{I}(\mathrm{TnI})$, troponin $\mathrm{T}(\mathrm{TnT})$, and myosin-binding protein 
$\mathrm{C}$ (MyBP-C), and also the $\mathrm{Ca}^{2+}$-dependence of tension development and ATPase activity in skinned right ventricular trabeculae obtained from TO-2 and F1B hamsters.

\section{MATERIALS AND METHODS}

Preparation. Skinned right ventricular trabeculae were prepared from 10- to 12-week-old male F1B and TO-2 hamsters $(109.4 \pm 8.5 \mathrm{~g}$ and $94.3 \pm 10.0 \mathrm{~g}$ in weight, respectively), treated in accordance with the Guiding Principles for the Care and Use of Animals in the Field of Physiology Science published by the Physiological Society of Japan, as described previously [14].

Experimental solutions. Solution compositions were calculated using the computer program, as in our earlier study [14]. The relaxing solution contained $(\mathrm{mmol} / \mathrm{l})$ EGTA 5.9; CaEGTA 0.1; MgATP 6.3; Mg-propionate 1.2; phosphate (Pi) 1; Na-propionate 27; K-propionate 49; phosphenol pyruvate (PEP) 15; nicotinamide adenine dinucleotide (NADH) 0.75; pyruvate kinase (PK) $100 \mathrm{U} / \mathrm{ml}$; lactate dehydrogenase (LDH) $140 \mathrm{U} / \mathrm{ml} ; \mathrm{NaN}_{3} 10$; diadenosine pentaphosphate $\left(\mathrm{A}_{2} \mathrm{P}_{5}\right) 0.2$; and MOPS $10(\mathrm{pH} 7.0$ at $22^{\circ} \mathrm{C}$ ). $\mathrm{NaN}_{3}$ and $\mathrm{A}_{2} \mathrm{P}_{5}$ were used to inhibit the mitochondrial ATPase and adenylate kinase activities, respectively. The preactivating solution had the same composition as that of the relaxing solution, except that the EGTA concentration was reduced to $0.1 \mathrm{mmol} / \mathrm{l}$. The activating solutions with the various $\mathrm{Ca}^{2+}$ concentrations were prepared by mixing the relaxing solution ( $\mathrm{pCa} 8.0)$ and a solution ( $\mathrm{pCa} 4.6$ ), in which EGTA in the relaxing solution was replaced by equimolar amounts of CaEGTA. In all solutions, total $\mathrm{Na}$ concentration was maintained at $78 \mathrm{mM}$; the MgATP concentration was maintained at $5 \mathrm{mM}$; both the $\mathrm{Pi}$ and $\mathrm{Mg}^{2+}$ concentrations were maintained at $1 \mathrm{mM}$; and the ionic strength was adjusted to $200 \mathrm{mM}$ with $\mathrm{K}$ propionate.

Experimental apparatus of mechanoenergetic measurements. The preparation was mounted horizontally in an experimental chamber (volume $40 \mu \mathrm{l}$ ) between stainless steel hooks connected to a tension transducer (AE 801, SensoNor, Horten, Norway) and a servocontrolled piezoelectric translator (PZT) (E-662, Physik Instrumente, Germany), with a fast-setting glue (collodion) via the loop of silk strand at either end of the preparation. Tension, length, and ATPase activity (NADH absorbance signal, see below) were recorded with an A/D converter (Powerlab/8SP, ADInstruments, Australia) connected to a PC (Mebius, SHARP, Japan). The experimental chamber had quartz windows to allow the transmission of near-ultraviolet light for the measurement of NADH absorbance. The NADH absorbance signal was measured with a dual wave length spectrophotometer (JASCO Co., Tokyo, Japan). The solutions in the chamber were constantly stirred with a small magnet during the experiments. The temperature of the solutions was kept at $22^{\circ} \mathrm{C}$ with an accuracy of $0.1^{\circ} \mathrm{C}$ by circulating temperature-controlled water through a brass block beneath the experimental chamber. Sarcomere length was measured by a light diffraction with He-Ne laser (model GLG 5350, NEC, Tokyo, Japan).

Measurement of ATPase activity. The ATPase activity of the preparation was measured by the method utilizing two enzymatic reactions [14]. One reaction is ADP + PEP $\rightarrow$ ATP + pyruvate, catalyzed by $\mathrm{PK}$, and the other reaction is pyruvate $+\mathrm{NADH} \rightarrow$ lactate $+\mathrm{NAD}$, catalyzed by $\mathrm{LDH}$. The ATPase activity associated with the $\mathrm{Ca}^{2+}$-activated tension development was obtained by subtracting the NADH absorbance change of the resting preparation from that of the $\mathrm{Ca}^{2+}$-activated preparation.

Determination of phosphorylation status of contractile proteins. After the measurements of tension development and ATPase activity, proteins were extracted from the individual preparations with $15 \mu$ of SDS sample buffer (75 $\mathrm{mM}$ Tris- $\mathrm{HCl}[\mathrm{pH} 6.8], 3 \%$ [w/v] SDS, $5 \%$ [v/v] 2-mercaptoethnol, $30 \%[\mathrm{v} / \mathrm{v}]$ glycerol, and $0.02 \%[\mathrm{w} / \mathrm{v}]$ bromophenol blue), and the whole quantity $(15 \mu \mathrm{l})$ of the extract was applied to 1D-PAGE on 10\%-20\% gradient polyacrylamide gels. Phosphorylated proteins were detected by Pro-Q Diamond stain according to the protocol of the supplier (Molecular Probes, Eugene, OR). Briefly, the gels were fixed in $10 \%$ acetic acid $/ 50 \%$ methanol and stained with Pro-Q Diamond $(1.5 \mathrm{~h})$. The gels were destained and scanned using a laser-scanning instrument (FLA-3000G, Fuji Photo Film, Tokyo, Japan) with a 532 $\mathrm{nm}$ laser for excitation source and a $580 \mathrm{~nm}$ long-pass emission filter. Subsequently, the gels were stained with SYPRO Ruby (Molecular Probes) overnight to visualize total proteins. They were destained with $10 \%$ methanol/ $7 \%$ acetic acid for $30 \mathrm{~min}$ and scanned on the laser-scanning instrument (FLA-3000G) using a $473 \mathrm{~nm}$ laser for excitation source and a $580 \mathrm{~nm}$ long-pass emission filter. After measuring the fluorescent intensities of the band for myosin light chain 2 (MLC2), troponin I (TnI), troponin T (TnT), and myosin-binding protein $\mathrm{C}(\mathrm{MyBP}-\mathrm{C})$ by using a densitometric analysis (Science Lab 99 Image Gauge, Fuji Photo Film), we calculated the ratio of Pro-Q Diamond dye to SYPRO Ruby dye signal intensities (Pro-Q/ SYPRO) for each band to normalize the phosphorylation level to the total amount of protein.

Experimental protocols. The preparation was first equilibrated for 5-10 $\mathrm{min}$ in the relaxing solution. Sarcomere length was adjusted to $2.2 \mu \mathrm{m}$ at which the resting tension was about $10 \%$ of the maximum active tension in the TO-2 and F1B preparations. At first, the stabilized preparation was activated twice with the maximum activating solution ( $\mathrm{pCa} 4.6)$ in the following sequential way of solution changes: relaxing solution, preactivating solution, maximum activating solution, and relaxing solution. This was to learn the amount of tension deterioration of the preparation. If the isometric tension of the second activation was greater than $90 \%$ of the first and the resting 
tension was returned to the initial level, the preparation was retained for the current experiments. It was then activated to contract isometrically with various $\mathrm{Ca}^{2+}$ concentrations over a range from $\mathrm{pCa} 8.0$ to $\mathrm{pCa} 4.6$.

Data analysis and statistical evaluation. Either tension or ATPase activity measured at submaximal $\mathrm{pCa}$ was expressed as a fraction of the respective maximum value. The individual relative pCa-tension and pCa-ATPase activity relations were characterized by Hill plot analysis, as described previously [14]. All data are presented as mean \pm SD. The statistical differences in the parameters of tension and ATPase activity between F1B and TO-2 preparations were determined by two-way ANOVA and those in the phosphorylation levels by unpaired $t$-test. $P$ values $<0.05$ were taken as indicating significant differences.

\section{RESULTS}

\section{$\mathrm{Ca}^{2+}$-dependence of isometric tension and ATPase activity}

Figure 1 shows the typical results of $\mathrm{Ca}^{2+}$-activated isometric tension (lower trace) and ATPase activity (upper trace) simultaneously obtained from an F1B preparation. After the amount of tension deterioration of the preparation was confirmed to be less than $10 \%$ by the second application of $\mathrm{pCa} 4.6$ maximum activating solution (see MATERIALS AND METHODS), the series of records was taken. As can be seen in Fig. 1, the ATPase activity, indicated as the slope representing the decrease of NADH, attained a steady value during the steady level of isometric tension for each pCa value used. The steady isometric ten-
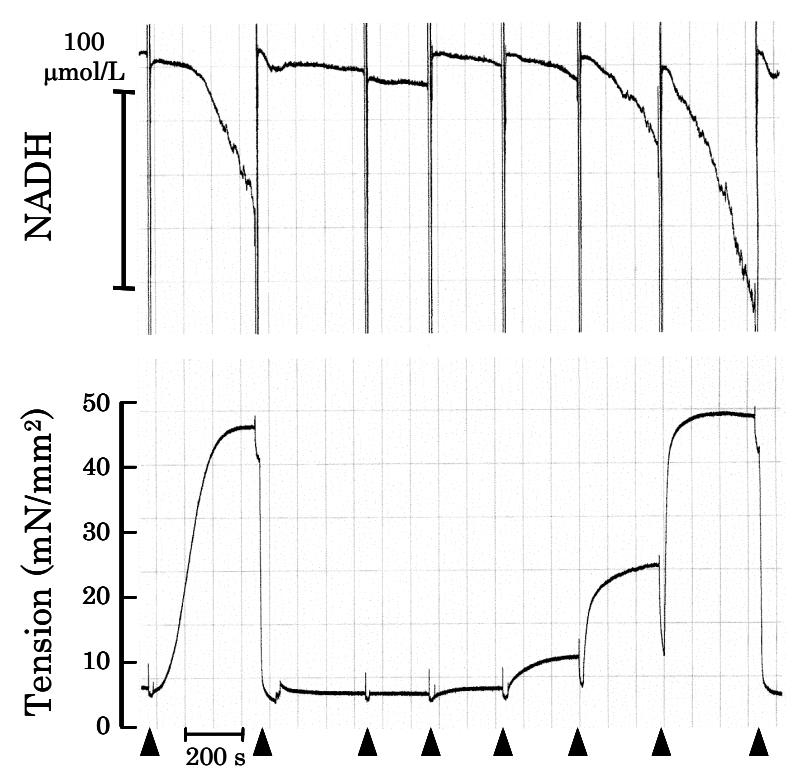

$\begin{array}{lllllllll}\mathrm{pCa} & 4.6 & \text { relax } & \text { pre } & 6.1 & 5.8 & 5.5 & 4.6 & \text { relax }\end{array}$

Fig. 1. Typical results of $\mathrm{Ca}^{2+}$-activated isometric tension (lower trace) and NADH absorbance changes (upper trace) in $\mathrm{F} 1 \mathrm{~B}$ preparation. sion and ATPase activity values (relative to the respective maximum value) were plotted against $\mathrm{pCa}$ values and were well fitted to the Hill equation (Fig. 2). Average fit parameters $\left(\mathrm{pCa}_{50}\right.$, the $\mathrm{Ca}^{2+}$ concentration required for half maximal value and Hill $n$, Hill coefficient) obtained individually from $8 \mathrm{~F} 1 \mathrm{~B}$ and $8 \mathrm{TO}-2$ preparations are shown in Table 1. The $\mathrm{Ca}^{2+}$ sensitivities of tension development and ATPase activity are seen to be significantly $(P$ $<0.0001$ ) higher in TO-2 than in F1B preparations with no difference in Hill $n$ between the two. However, no significant difference in their maximum values was observed between TO-2 $\left(40.8 \pm 7.4 \mathrm{mN} / \mathrm{mm}^{2}\right.$ in tension and $0.52 \pm$ $0.15 \mu \mathrm{mol} / / / \mathrm{s}$ in ATP consumption) and F1B (42.3 \pm 8.5

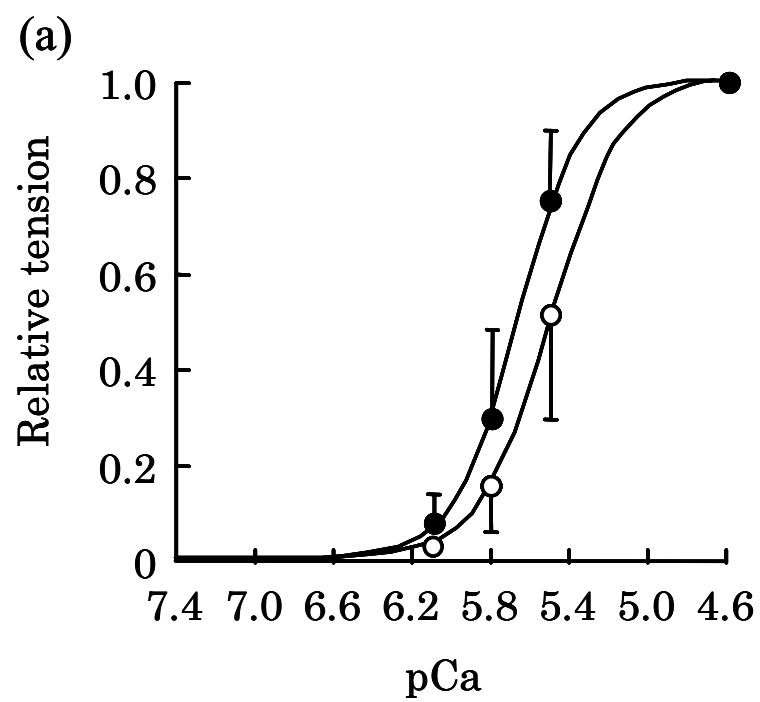

(b)

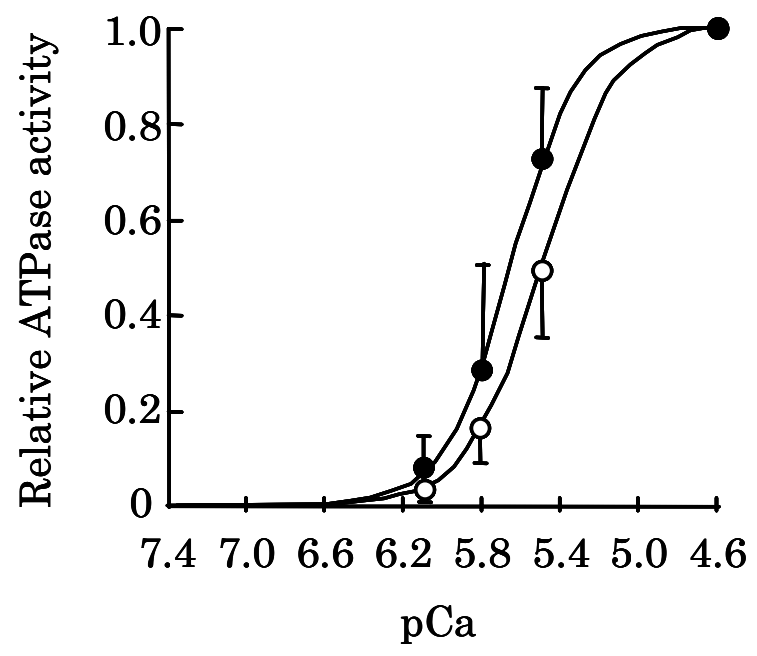

Fig. 2. Average $\mathrm{Ca}^{2+}$ sensitivity of tension (a) and ATPase activity (b) in the F1B (open circles) and TO-2 (closed circles) preparations. Average (mean $\pm \mathrm{SD}, n=8$ ) tension and ATPase activity values (relative to the respective maximum value) were plotted against $\mathrm{pCa}$ values, and the data were fitted to the Hill equation, as indicated by solid lines. Average fit parameters obtained individually from 8 preparations are shown in Table 1. 
Table 1. Average Hill fit parameters in F1B and TO-2 preparations.

\begin{tabular}{llll}
\hline & & \multicolumn{1}{c}{ F1B } & \multicolumn{1}{c}{ TO-2 } \\
\hline Isometric tension & $\mathrm{pCa}_{50}$ & $5.48 \pm 0.03$ & $5.64 \pm 0.04^{*}$ \\
& Hill $n$ & $2.81 \pm 0.25$ & $2.92 \pm 0.31$ \\
ATPase activity & $\mathrm{pCa}_{50}$ & $5.51 \pm 0.03$ & $5.65 \pm 0.04^{*}$ \\
& $\mathrm{Hill} n$ & $2.78 \pm 0.22$ & $2.87 \pm 0.29$ \\
\hline
\end{tabular}

pCa50 indicates the $\mathrm{Ca}^{2+}$ concentration required for half maximal value. Hill $n$ indicates Hill coefficient. Values are mean $\pm \mathrm{SD}, n=$ 8. ${ }^{*} P<0.0001$ by two-way ANOVA.

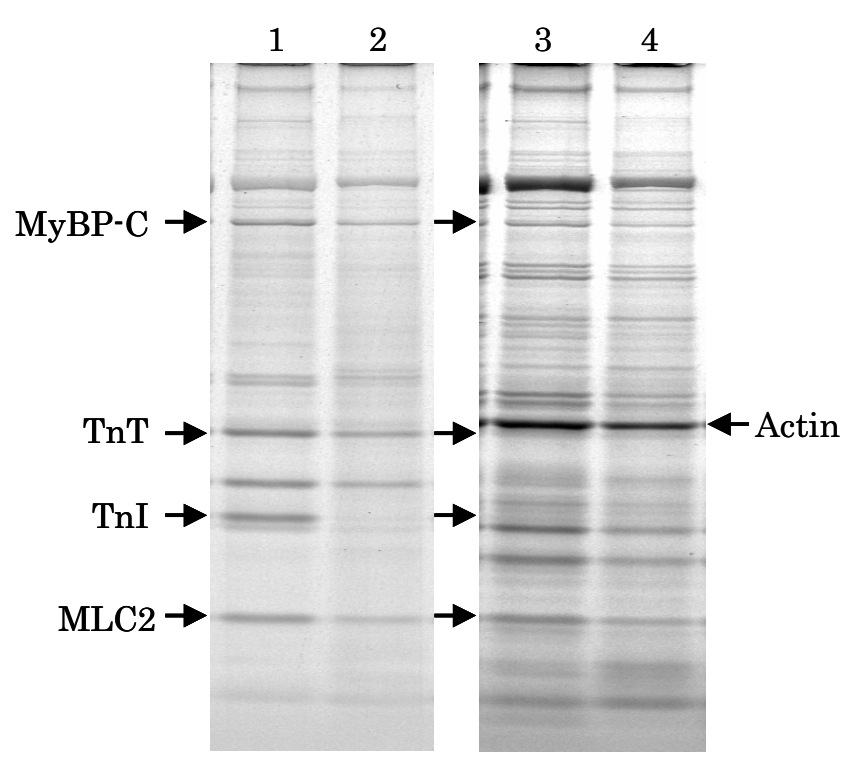

Fig. 3. Typical SDS-PAGE patterns $(10 \%-20 \%$ gradient gel) for F1B (lanes 1 and 3) and TO-2 (lanes 2 and 4) preparations. The gel was stained with Pro-Q Diamond (lanes 1 and 2) specifically for phosphorylated proteins and subsequently stained with SYPRO Ruby (lanes 3 and 4 ) for total proteins.

$\mathrm{mN} / \mathrm{mm}^{2}$ in tension and $0.58 \pm 0.41 \mu \mathrm{mol} / / / \mathrm{s}$ in ATP consumption) preparations, indicating that the tension cost (ATPase activity/tension development) in TO-2 preparations was quite similar to that in F1B preparations. The tension cost at submaximum activation was also almost the same between two preparations, though the data were not shown.

\section{Phosphorylation status of contractile proteins}

Figure 3 shows typical patterns of SDS-PAGE $(10 \%-$ $20 \%$ gradient gel) of skinned-trabeculae obtained from F1B (lanes 1 and 3) and TO-2 (lanes 2 and 4) hamsters. The gels were stained with Pro-Q Diamond (lanes 1 and 2) specific for phosphorylated proteins and subsequently with SYPRO Ruby (lanes 3 and 4) for total proteins. The Pro-Q Diamond stained gel shows prominent bands of phosphorylated proteins corresponding to myosin light chain 2 (MLC2), troponin I (TnI), troponin T (TnT), and myosin-binding protein C (MyBP-C), while the SYPRO

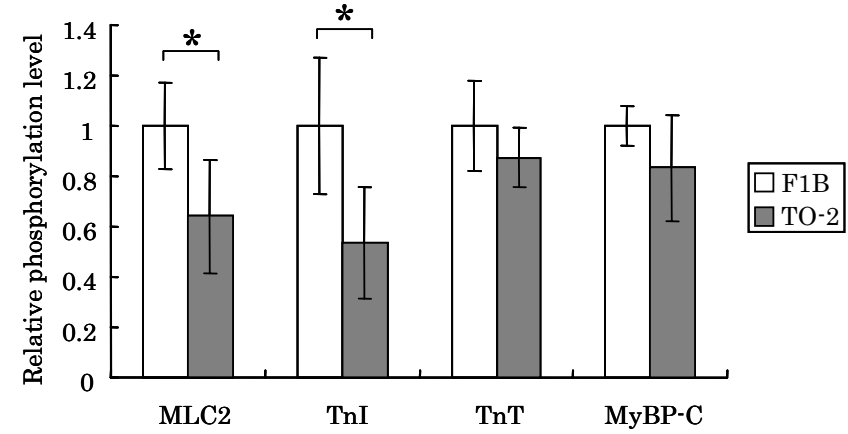

Fig. 4. Bar graph showing the relative phosphorylation levels of MLC2, Tnl, TnT, and MyBP-C in the F1B (white columns) and the TO-2 (black columns) preparations. Each column and vertical bar represents the mean $\pm S D$ of eight preparations. The averaged mean value for each contractile protein in TO-2 preparations is normalized to the respective mean value in F1B preparations. ${ }^{*} P<0.01$ by unpaired $t$-test.

Ruby stained gel shows the protein bands of MLC2, TnI, TnT, actin, and MyBP-C. After measuring the fluorescent intensities of protein bands for MLC2, TnI, TnT, and MyBP-C, we calculated the intensity ratio of Pro-Q Diamond dye to SYPRO Ruby dye (Pro-Q/SYPRO) for each protein to normalize the phosphorylation level relative to each corresponding protein's content.

To assess the possible degradation of these regulatory proteins in TO-2 as compared with F1B hearts, we also calculated the band intensity ratio of SYPRO Ruby stained gels for MLC2, TnI, TnT, and MyBP-C relative to the corresponding actin in F1B and TO-2 preparations. We found no significant difference in the band intensity ratio (mean $\pm \mathrm{SD}, n=8$ ) between $\mathrm{F} 1 \mathrm{~B}$ and TO-2 preparations (MLC2/actin $=0.16 \pm 0.03$ in $\mathrm{F} 1 \mathrm{~B}$ and $0.17 \pm 0.03$ in TO-2; likewise, TnI/actin $=0.074 \pm 0.011$ vs. $0.072 \pm$ $0.015, \mathrm{TnT} /$ actin $=0.097 \pm 0.016$ vs. $0.108 \pm 0.014$, MyBP-C/actin $=0.074 \pm 0.015$ vs. $0.070 \pm 0.011$ ), showing no apparent degradation of these regulatory proteins in TO-2 as compared with F1B hearts.

Figure 4 shows the phosphorylation levels of MLC2, TnI, TnT, and MyBP-C in TO-2 preparations relative to those of the respective protein in F1B preparations. Each column and vertical bar represents the mean \pm SD of 8 preparations. As clearly seen in Fig. 3, the phosphorylation levels of MLC2 and TnI were significantly $(P<0.01)$ lower in TO-2 than in F1B preparations. Although the average values of TnT and MyBP-C phosphorylation levels were lower in TO-2 than in F1B preparations, no significant differences in their phosphorylation levels were observed between the two preparations.

\section{DISCUSSION}

In the present study, we found that (1) the $\mathrm{Ca}^{2+}$ sensitivities of tension development and ATPase activity were 
higher in TO-2 than in F1B cardiac trabeculae (Table 1), and that (2) the phosphorylation levels of MLC2 and TnI were lower in TO-2 than in F1B cardiac trabeculae (Fig. 4). These results strongly suggest that the increased $\mathrm{Ca}^{2+}$ sensitivities of tension and ATPase activity in TO-2 cardiac trabeculae are largely due to the lower phosphorylation level of TnI [15-19], since the lower phosphorylation of MLC2 is reported to decrease the $\mathrm{Ca}^{2+}$ sensitivity of tension development [20-22]. The data similar to the present results have been reported in human dilated cardiomyopathies [18] and in end-stage human failing myocardium [23]. Velden et al. [23] observed that as compared with nonfailing myocardium, the $\mathrm{Ca}^{2+}$ sensitivity of tension development $\left(\mathrm{pCa}_{50}\right)$ was significantly higher in failing myocardium with an increased percentage of dephosphorylated $\mathrm{TnI}$ and an inverse correlation between $\mathrm{pCa}_{50}$ and a percentage of phosphorylated MLC2. Further, protein kinase A (PKA) was reported to decrease $\mathrm{Ca}^{2+}$ sensitivity to a large extent because of the greater changes in $\mathrm{TnI}$ phosphorylation level in failing than in nonfailing myocytes.

No difference in the phosphorylation level of TnT between nonfailing and failing hearts was also reported to be observed, as in the present and recent [19] studies. The lower phosphorylation levels of MLC2 and TnI in TO-2 heart as compared with those of F1B heart (Fig. 4) therefore seem to be due to the decreased PKA activity and/or the increased protein phosphatase activity $[18,22]$. Actually, an expression of cardiac phosphatases has been reported to increase in patients with end-stage heart failure [24]. Neuman et al. [24] reported a 2.5-fold increase in phosphatase activity in the membrane fraction of failing heart, which was linked to decreased levels of phosphatase inhibitor-1 and decreased phosphatase inhibitor-1 phosphorylation by PKA, both of which lead to higher phosphatase activity [25, 26]. Furthermore, a reduction in the number of $\beta$-adrenoceptors and an increased activity of inhibitory $\mathrm{G}$ protein that couple in an inhibitory fashion to adenyl cyclase activity have been reported to be involved in end-stage human heart failure [27-29]. In accordance with these findings, the $\beta$-adrenoceptor-mediated increase in cAMP levels is known to be smaller in patients with failing than in those with nonfailing hearts [30]. Feldman et al. [31] also observed a decrease in isoprenaline-mediated cAMP formation, resulting from a disturbed function of the Gs-protein in 100-day-old TO-2 hamster hearts. Thus the same seems to be true in TO-2 heart as in end-stage human heart failure.

Since the cross-bridge cycling rate, which is reflected as the tension cost [32], has been reported to be slower at lower TnI [14, 33] and MLC2 [34] phosphorylation level, the tension cost of a TO-2 heart should be lower than that of an F1B heart. No difference in the tension cost between the present two preparations imply that the cross-bridge cycling rate of the TO-2 heart decreased by lower TnI and
MLC2 phosphorylation might be increased nearly to that of the F1B heart by some factors. One factor might be the $\mathrm{TnI}$ phosphorylation at protein kinase C (PKC) sites, which has been reported to change the cross-bridge cycling rate opposing to the TnI phosphorylation at PKA sites [35]. The other possible factor might be related to the gene defect in $\delta$-sarcoglycan in TO-2 hearts, which increases the cross-bridge cycling rate through unknown mechanisms. Quite recently, the primary effect of the PKA phosphorylation of $\mathrm{TnI}$ has been reported to be related only to the reduced $\mathrm{Ca}^{2+}$ sensitivity of tension, and not to the cross-bridge kinetics [36]. If this is so in the present preparations, the different TnI phosphorylation level between TO-2 and F1B preparations might not relate to their tension cost.

In our earlier study [7], the calcium transients measured by Indo- 1 was found to reveal elevated diastolic levels, decreased peak levels, and slower diastolic decay in TO-2 myocytes as compared with F1B myocytes. From these results together with the previous similar findings $[12,13]$, the contractile dysfunctions in TO-2 heart have been considered to be caused mostly by the impairment of the sarcoplasmic reticulum calcium transport function. The present results, the increase in $\mathrm{Ca}^{2+}$ sensitivities of tension development and the ATPase activity associated with the decreased basal level of TnI phosphorylation, can thus, be considered to produce the incomplete diastolic relaxation and partly improve the systolic function in TO-2 hearts.

A part of this study was supported by a grant from the Japanese Ministry of Education, Culture, Sports, Science and Technology of Japan (Academic Frontier Project, 2003-2007).

\section{REFERENCES}

1. Dec GW, Fuster V. Idiopathic dilated cardiomyopathy. N Engl J Med. 1994;331:1564-75.

2. Panchal BC, Trippodo NC. Systemic and regional haemodynamics in conscious BIO T0-2 cardiomyopathic hamsters. Cardiovasc Res. 1993;27:2264-9.

3. Witte K, Schnecko A, Hauth D, Wirzius S, Lemmer B. Effects of chronic application of propranolol on $\beta$-adrenergic signal transduction in heart ventricles from myopathic BIO TO2 and control hamsters. Br J Pharmacol. 1998;125:103341.

4. Goineau S, Pape D, Guillo P, Ramee MP, Bellissant E. Hemodynamic and histomorphometric characteristics of dilated cardiomyopathy of Syrian hamsters (Bio TO-2 strain). Can J Physiol Pharmacol. 2001;79:329-37.

5. Iwase M, Kanazawa H, Kato Y, Nishizawa T, Somura F, Ishiki R, Nagata K, Hashimoto K, Takagi K, Izawa H, Yokota M. Growth hormone-releasing peptide can improve left ventricular dysfunction and attenuate dilation in dilated cardiomyopathic hamsters. Cardiovasc Res. 2004;61:30-8.

6. Nishizawa T, Iwase M, Kanazawa H, Ichihara S, Ichihara G, Nagata K, Obata K, Kitaichi K, Yokoi T, Watanabe M, Tsunematsu T, Ishikawa Y, Murohara T, Yokota M. Serial alterations of $\beta$-adrenergic signaling in dilated cardiomyopathic hamsters: possible role of myocardial oxidative stress. Circ J. 2004;68:1051-60.

7. Nishimura S, Yamashita H, Katoh M, Yamada KP, Sunagawa K, Saeki Y, Ohnuki $Y$, Nagai R, Sugiura S. Contractile dysfunction of cardiomyopathic hamster myocytes is pronounced under high load conditions. $\mathrm{J} \mathrm{Mol} \mathrm{Cell} \mathrm{Cardiol.}$ 2005;39:231-9

8. Sakamoto A, Ono K, Abe M, Jasmin G, Eki T, Murakami Y, Masaki T, Toyo-oka T, Hanaoka F. Both hypertrophic and dilated cardiomyopathies are caused by mutation of the same gene, $\delta$-sarcoglycan, in hamster: an animal model of 
disrupted dystrophin-associated glycoprotein complex. Proc Natl Acad Sci USA. 1997;94:13873-8.

9. Sakamoto A, Abe M, Masaki T. Delineation of genomic deletion in cardiomyopathic hamster. FEBS Lett. 1999;447:124-8.

10. Tsubata S, Bowles KR, Vatta M, Zintz C, Titus J, Muhonen L, Bowles NE, Towbin JA. Mutations in the human $\delta$-sarcoglycan gene in familial and sporadic dilated cardiomyopathy. J Clin Invest. 2000;106:655-62.

11. Malhotra A, Karell M, Scheuer J. Multiple cardiac contractile protein abnormalities in myopathic Syrian hamsters (BIO 53 : 58). J Mol Cell Cardiol. 1985;17:95-107.

12. Whitmer JT, Kumar P, Solaro RJ. Calcium transport properties of cardiac sarcoplasmic reticulum from cardiomyopathic Syrian hamsters (BIO 53.58 and 14.6): evidence for a quantitative defect in dilated myopathic hearts not evident in hypertrophic hearts. Circ Res. 1988;62:81-5.

13. Anger M, Lambert F, Chemla D, Desche P, Scalbert E, Lompre AM, Lecarpentier Y. Sarcoplasmic reticulum $\mathrm{Ca}^{2+}$ pumps in heart and diaphragm of cardiomyopathic hamster: effects of perindopril. Am J Physiol. 1995;268:H194753.

14. Saeki Y, Kobayashi T, Minamisawa S, Sugi H. Protein kinase A increases the tension cost and unloaded shortening velocity in skinned rat cardiac muscle. $J$ Mol Cell Cardiol. 1997;29:1655-63.

15. Robertson SP, Johnson JD, Holroyde MJ, Kranias EG, Potter JD, Solaro RJ. The effect of troponin I phosphorylation on the $\mathrm{Ca}^{2+}$-binding properties of the $\mathrm{Ca}^{2+}$ regulatory site of bovine cardiac troponin. J Biol Chem. 1982;257:260-3.

16. Hofmann PA, Lange JH 3rd. Effects of phosphorylation of troponin I and C protein on isometric tension and velocity of unloaded shortening in skinned single cardiac myocytes from rats. Circ Res. 1994;74:718-26.

17. Noland TA Jr, Guo X, Raynor RL, Jideama NM, Averyhart-Fullard V, Solaro RJ, Kuo JF. Cardiac troponin I mutants. Phosphorylation by protein kinases $\mathrm{C}$ and $\mathrm{A}$ and regulation of $\mathrm{Ca}^{2+}$-stimulated MgATPase of reconstituted actomyosin S-1. J Biol Chem. 1995;270:25445-54.

18. Wolff MR, Buck SH, Stoker SW, Greaser ML, Mentzer RM. Myofibrillar calcium sensitivity of isometric tension is increased in human dilated cardiomyopathies: role of altered $\beta$-adrenergically mediated protein phosphorylation. J Clin Invest. 1996;98:167-76.

19. Messer AE, Jacques AM, Marston SB. Troponin phosphorylation and regulatory function in human heart muscle: dephosphorylation of Ser23/24 on troponin I could account for the contractile defect in end-stage heart failure. J Mol Cell Cardiol. 2007;42:247-59.

20. Morano I, Arndt H, Bachle-Stolz C, Ruegg JC. Further studies on the effects of myosin $\mathrm{P}$-light chain phosphorylation on contractile properties of skinned cardiac fibres. Basic Res Cardiol. 1986;81:611-9.

21. Noland TA Jr, Kuo JF. Phosphorylation of cardiac myosin light chain 2 by protein kinase $\mathrm{C}$ and myosin light chain kinase increases $\mathrm{Ca}^{2+}$-stimulated actomyosin MgATPase activity. Biochem Biophys Res Commun. 1993;193:254-60.

22. van der Velden J, Papp Z, Boontje NM, Zaremba R, de Jong JW, Janssen PM, Hasenfuss $G$, Stienen GJ. The effect of myosin light chain 2 dephosphorylation on $\mathrm{Ca}^{2+}$-sensitivity of force is enhanced in failing human hearts. Cardiovasc Res.
2003;57:505-14.

23. van der Velden J, Papp Z, Zaremba R, Boontje NM, de Jong JW, Owen VJ, Burton PB, Goldmann P, Jaquet K, Stienen GJ. Increased $\mathrm{Ca}^{2+}$-sensitivity of the contractile apparatus in end-stage human heart failure results from altered phosphorylation of contractile proteins. Cardiovasc Res. 2003;57:37-47.

24. Neumann J, Eschenhagen T, Jones LR, Linck B, Schmitz W, Scholz H, Zimmermann N. Increased expression of cardiac phosphatases in patients with end-stage heart failure. J Mol Cell Cardiol. 1997;29:265-72.

25. Carr AN, Schmidt AG, Suzuki Y, del Monte F, Sato Y, Lanner C, Breeden K, Jing SL, Allen PB, Greengard P, Yatani A, Hoit BD, Grupp IL, Hajjar RJ, DePaoliRoach AA, Kranias EG. Type 1 phosphatase, a negative regulator of cardiac function. Mol Cell Biol. 2002;22:4124-35.

26. El-Armouche A, Pamminger T, Ditz D, Zolk O, Eschenhagen T. Decreased protein and phosphorylation level of the protein phosphatase inhibitor-1 in failing human hearts. Cardiovasc Res. 2004;61:87-93.

27. Bristow MR, Ginsburg R, Minobe W, Cubicciotti RS, Sageman WS, Lurie K, Billingham ME, Harrison DC, Stinson EB. Decreased catecholamine sensitivity and $\beta$-adrenergic-receptor density in failing human hearts. N Engl J Med. 1982;307:205-11.

28. Bristow MR, Minobe W, Rasmussen R, Larrabee P, Skerl L, Klein JW, Anderson FL, Murray J, Mestroni L, Karwande SV, Fowler M, Ginsburg R. $\beta$-adrenergic neuroeffector abnormalities in the failing human heart are produced by local rather than systemic mechanisms. J Clin Invest. 1992;89:803-15.

29. Bristow MR, Minobe WA, Raynolds MV, Port JD, Rasmussen R, Ray PE, Feldman AM. Reduced $\beta_{1}$ receptor messenger RNA abundance in the failing human heart. J Clin Invest. 1993;92:2737-45.

30. Movsesian MA. Altered cAMP-mediated signalling and its role in the pathogenesis of dilated cardiomyopathy. Cardiovasc Res. 2004;62:450-9.

31. Feldman AM, Tena RG, Kessler PD, Weisman HF, Schulman SP, Blumenthal RS, Jackson DG, Van Dop C. Diminished $\beta$-adrenergic receptor responsiveness and cardiac dilation in hearts of myopathic Syrian hamsters (BIO 53.58) are associated with a functional abnormality of the $\mathrm{G}$ stimulatory protein. Circulation. 1990;81:1341-52.

32. Brenner $\mathrm{B}$. Effect of $\mathrm{Ca}^{2+}$ on cross-bridge turnover kinetics in skinned single rabbit psoas fibers: implications for regulation of muscle contraction. Proc Natl Acad Sci USA. 1988;85:3265-9.

33. Kentish JC, McCloskey DT, Layland J, Palmer S, Leiden JM, Martin AF, Solaro RJ. Phosphorylation of troponin I by protein kinase $A$ accelerates relaxation and crossbridge cycle kinetics in mouse ventricular muscle. Circ Res 2001;88:105965.

34. Stelzer JE, Patel JR, Moss RL. Acceleration of stretch activation in murine myocardium due to phosphorylation of myosin regulatory light chain. J Gen Physiol. 2006;128:261-72.

35. Layland J, Solaro RJ, Shah AM. Regulation of cardiac contractile function by troponin I phosphorylation. Cardiovasc Res. 2005;66:12-21.

36. Stelzer JE, Patel JR, Walker JW, Moss RL. Differential roles of cardiac myosinbinding protein $\mathrm{C}$ and cardiac troponin I in the myofibrillar force responses to protein kinase A phosphorylation. Circ Res. 2007;101:503-11. 